\title{
A IMPORTÂNCIA DO AJUSTE MENSAL DA INCLINAÇÃO DO COLETOR SOLAR
}

\author{
L. P. FURMAN ${ }^{1}$, L. BARTMER ${ }^{1}$, M. E. S. TAQUEDA ${ }^{2}$, W. M. SALVAGNINI ${ }^{2}$, T. R. \\ SOUZA $^{1}$
}

${ }^{1}$ Universidade Federal do Pampa, Departamento de Engenharia Química, Campus Bagé

${ }^{2}$ Universidade de São Paulo, São Paulo.

E-mail para contato: leonardoparanaeq@gmail.com

\begin{abstract}
RESUMO - Uma comparação entre números de coletores solares instalados na Alemanha e no Brasil nos dá uma ideia de quanto o Brasil pode ampliar o uso de energia solar. Na Alemanha, um país com 80 milhões de habitantes e clima extremamente frio, existem quatro milhões de metros quadrados de coletores solares instalados, enquanto que no Brasil, com uma população de quase 184 milhões de habitantes e clima propício para o uso da energia solar, há somente três milhões de metros quadrados. O coletor solar é um dispositivo que promove o aquecimento de um fluido através da conversão da radiação eletromagnética, proveniente do Sol, em energia térmica. São constituídos por uma placa plana inclinada, pintada de preto, com algumas camadas de isolante para garantir que todo calor permaneça na superfície da placa. O presente trabalho de pesquisa teve o objetivo de verificar se o ajuste de inclinação de um coletor solar influencia sua eficiência. Os experimentos foram realizados seguindo um planejamento fatorial $2^{2}$ com 6 repetições do ponto central, para cada horário do dia. As variáveis de entrada foram: a vazão do fluído de alimentação e a inclinação da placa e a variável de saída foi a taxa de evaporação. Verificou-se que o ajuste da inclinação da placa proporciona elevação de até $36,4 \%$ na porcentagem de evaporação, justificando a necessidade do ajuste mensal.
\end{abstract}

\section{INTRODUÇÃO (FONTE 14)}

O planeta Terra recebe diariamente uma enorme quantidade de energia solar e o Brasil apresenta uma grande extensão territorial na faixa equatorial e tropical, recebendo grande parcela dessa energia. Ao longo do tempo, o ser humano se preocupou em aproveitar a energia solar transformando-a em outras formas de energia, como a térmica, mecânica e elétrica, desenvolvendo diferentes tecnologias para aquecer água, mover moinhos e barcos, cozinhar alimentos e atualmente produzir eletricidade.

Embora o uso da energia solar apresente alguns pontos negativos (o elevado custo dos materiais, indústria brasileira despreparada, descrença por parte da sociedade e grande área necessária para a instalação dos coletores), os pontos positivos (a tecnologia empregada no aproveitamento da energia solar é simples e está ao alcance de todos os países; a energia solar não polui e nem prejudica o ecossistema, a energia solar não necessita ser extraída, refinada e nem transportada para o local onde será utilizada e a energia solar é abundante, renovável a cada dia, permanente e gratuita) ainda prevalecem (Kalogirou, 2003). 
O aproveitamento térmico para aquecimento de fluidos é feito com o uso de coletores ou concentradores solares. Os coletores solares são mais usados em aplicações residenciais e comerciais (hotéis, restaurantes, clubes, hospitais etc.) para o aquecimento de água (higiene pessoal e lavagem de utensílios e ambientes). Os concentradores solares destinam-se a aplicações que requerem temperaturas mais elevadas, como a secagem de grãos e a produção de vapor (Palz, 1981).

Para aquecimento de fluidos até temperaturas da ordem de $150^{\circ} \mathrm{C}$, recomenda-se o uso de coletores planos, que geralmente são constituídos por uma placa plana, pintada de preto (para maior absorção da radiação solar), com algumas camadas de isolante para garantir que todo calor permaneça na superfície da placa, pode ter uma cobertura de vidro ou não de acordo com sua aplicação. Para maximizar o aproveitamento da radiação solar, deve-se ajustar a posição do coletor ou painel solar de acordo com a latitude local e o período do ano em que se requer mais energia. No Hemisfério Sul, por exemplo, um sistema de captação solar fixo deve ser orientado para o Norte, com ângulo de inclinação similar ao da latitude local (Duffie e Beckman, 1980).

Porém alguns trabalhos como Palz (1981), Tiris e Tiris (1998) e Hartley et al. (1999) ressaltam que a absorção da radiação solar variam ao longo do ano e também de acordo com a inclinação do coletor.

O presente trabalho de pesquisa tem o objetivo de verificar se o ajuste de inclinação de um coletor solar.

\section{METODOLOGIA}

Foi desenvolvido e construído um evaporador solar, cujo esquema de funcionamento pode ser visualizado na Figura 1. Esse equipamento consta de: coletor solar tipo placa plana (1), com promotor de película aderido à superfície do coletor (2), distribuidor de líquidos (3), coletor de concentrados (4) e acessórios.

Figura 1 - Esquema do equipamento

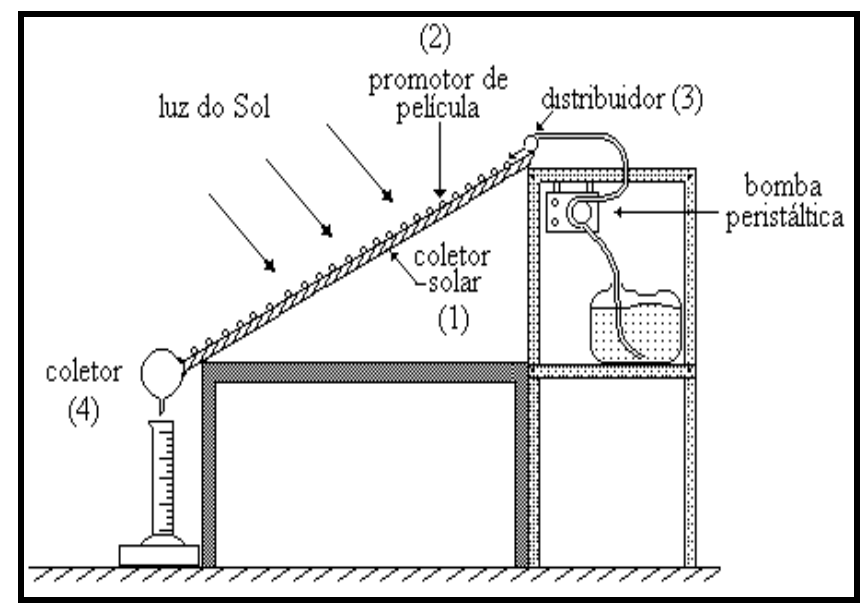

O coletor solar utilizado neste estudo mediu $150 \mathrm{~cm}$ x $70 \mathrm{~cm}$, portanto, têm-se 1,05 $\mathrm{m}^{2}$ de área disponível para a coleta de radiação solar. A placa plana foi feita de madeira, 
impermeabilizada (com neutrol) e pintada com tinta preta fosca, para aumentar a absorção da radiação solar que incida sobre ela. A madeira foi o material escolhido, pois apresenta preço acessível, fácil aquisição em qualquer localização do país e baixa condutibilidade térmica.

Todos os experimentos foram realizados em ambiente aberto, na cobertura do prédio semi-industrial do departamento de Engenharia Química da Universidade de São Paulo, sendo influenciados pelas variações ambientais.

A realização dos experimentos foi nos meses de outubro à março, em dias de sol pleno (sem nuvens), pois em dias nublados a taxa de evaporação foi menor que em dias sem nebulosidade, em decorrência da elevação da irradiância difusa. $\mathrm{O}$ objetivo de realizar todos os experimentos em dias parecidos foi manter a quantidade de radiação solar incidente o mais similar possível, em todos os dias que se realizaram os experimentos, atenuando os efeitos da diferença de incidência da radiação solar.

A realização de experimentos em dias chuvosos não foi possível, pois como dito anteriormente os ensaios foram realizados em ambiente aberto. Vale a pena ressaltar que a série de experimentos desconsiderou o horário de verão. Todos os experimentos foram realizados de forma contínua das 9:00 as 16:00 horas, para verificar como o equipamento se comportava no decorrer de todo o dia.

As medições dos dados experimentais, tais como: temperatura ambiente, umidade relativa, pressão atmosférica, temperatura do fluido (na entrada e na saída da placa) e vazão mássica do fluido (na entrada e na saída da placa) foram realizadas de hora em hora.

Com os valores das vazões mássicas na entrada e saída da placa plana, foi possível a obtenção da taxa de água evaporada com o balanço de massa apresentado pela Equação 1.

$$
\mathrm{W}_{\mathrm{ae}}=\mathrm{W}_{\mathrm{i}}-\mathrm{W}_{\mathrm{f}}
$$

onde $\mathrm{W}_{\mathrm{ae}}$ é a taxa de água evaporada (g/s), $\mathrm{W}_{\mathrm{i}}$ é a vazão mássica do líquido na entrada da placa $(\mathrm{g} / \mathrm{s})$ e $\mathrm{W}_{\mathrm{f}}$ é a vazão mássica do líquido na saída da placa $(\mathrm{g} / \mathrm{s})$.

A porcentagem de água evaporada foi determinada pela Equação 2.

$$
\% \mathrm{AE}=\frac{W_{\mathrm{ae}}}{W_{\mathrm{i}}} \cdot 100
$$

onde \%AE é a porcentagem de água evaporada (\%).

Após testes preliminares de funcionamento do equipamento e verificação da influência das variáveis, foi realizada uma série experimental baseada em Box et al. (1978), de um planejamento fatorial $2^{2}$ com 6 repetições, para cada horário do dia.

As variáveis de entrada foram: a vazão do fluído de alimentação e a inclinação da placa e a variável de saída foi a taxa de evaporação. É necessário lembrar que as variáveis meteorológicas também interferem na taxa de evaporação, porém não foram escolhidas como variáveis de entrada, pelo fato de não poderem ser controladas. 
A escolha do nível mínimo e máximo da inclinação da placa se fez baseado em informações encontradas na literatura. $\mathrm{O}$ valor de inclinação de $20^{\circ}$ foi estipulado pelo fato da maioria dos artigos publicados no Brasil fixarem o equipamento no valor de inclinação próximo a latitude de São Paulo $\left(23^{\circ} 33^{\prime} \mathrm{S}\right)$ e o valor de inclinação de $60^{\circ}$ foi estipulado como valor máximo, pois acima deste valor o escoamento foi muito rápido desfavorecendo a evaporação.

Foram estabelecidos dois procedimentos experimentais para verificar a importância de se adequar à inclinação da placa plana, mensalmente: no procedimento 1 a placa plana foi fixada na inclinação determinada em experimentos anteriores, conforme a Tabela 1, e a vazão foi variada de $1,5 \mathrm{a} 4,5 \mathrm{~g} / \mathrm{s}$ para verificar o comportamento do equipamento frente à variação de vazão de alimentação.

Tabela 1 - Valores obtidos da melhor inclinação para os meses de experimentos

\begin{tabular}{|c|c|c|c|}
\hline Meses & $\begin{array}{c}\text { Melhor } \\
\text { inclinação para } \\
\text { São Paulo - } \\
\text { Brasil }\end{array}$ & $\begin{array}{c}\text { Melhor } \\
\text { inclinação para } \\
\text { Gebze - Turquia } \\
\text { (Tiris and Tiris, } \\
1998)\end{array}$ & $\begin{array}{c}\text { Melhor } \\
\text { inclinação para } \\
\text { Valência - } \\
\text { Espanha } \\
\text { (Hartley } \text { et al. } \\
1999)\end{array}$ \\
\hline \hline Janeiro & 0,0 & 61,0 & 58,5 \\
\hline Fevereiro & 1,5 & 51,0 & 49,0 \\
\hline Março & 15,0 & 37,0 & 35,0 \\
\hline Outubro & 6,0 & 48,0 & 45,5 \\
\hline Novembro & 0,0 & 60,0 & 60,0 \\
\hline Dezembro & 0,0 & 62,0 & 61,0 \\
\hline
\end{tabular}

Um outro fato a se notar, é que os valores de inclinação da cidade de São Paulo diferem dos valores mais elevados para por Tiris e Tiris (1998) e para Hartley et al. (1999). Esse fato ocorre porque as cidades situam-se em diferentes Hemisférios

No procedimento 2 a placa foi fixada no valor de $\left(20,5^{\circ}\right)$ e a vazão foi fixada no valor em que se obtiveram maiores valores de taxa de evaporação no procedimento 1 , para verificar quanto o valor da taxa de evaporação foi afetado se a inclinação for fixa durante o ano todo e não ser ajustada mensalmente.

A análise dos planejamentos experimentais (estimativa de efeitos e ANOVA da regressão) foi obtida pelo software MINITAB, para a resposta da \% de evaporação. A partir desses dados efetuou-se uma interpretação para verificação da significância ou não do efeito das variáveis e de suas iterações, bem como, a adequação do modelo de regressão através do coeficiente de determinação e da análise de resíduos.

\section{RESULTADOS}

Os resultados experimentais (para os meses do experimento) obtidos a partir do procedimento 1 podem ser visualizados na Figura 2. 
Figura 2 - Porcentagem de água evaporada em função do horário.

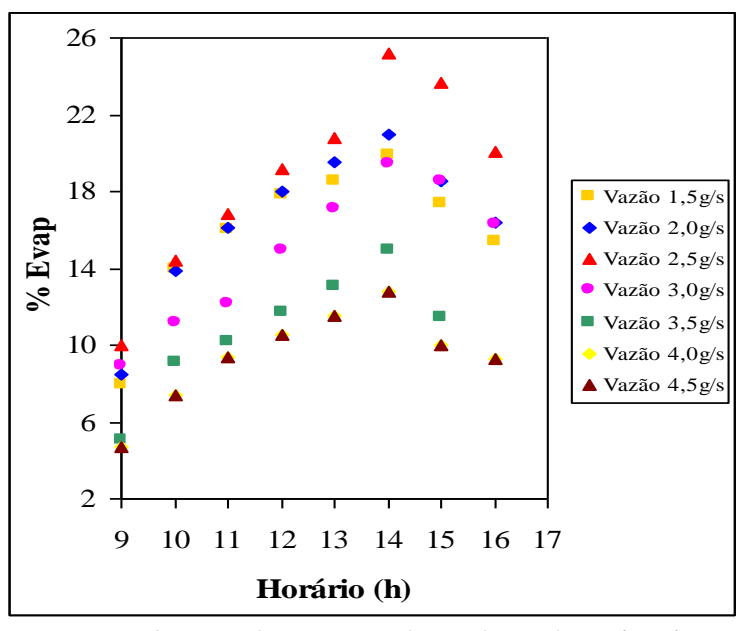

(a) Meses de: outubro, novembro, dezembro, janeiro e fevereiro.

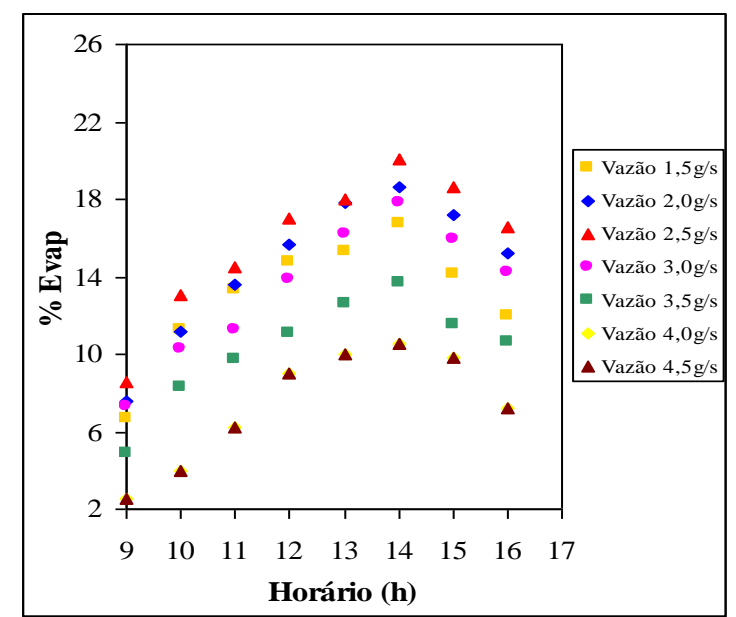

(b) Mês de março.

Nota-se que os valores mais elevados ocorrem por volta das 14:00 horas, para todos os meses do ano. Neste horário, geralmente o ambiente apresenta-se com maiores valores de temperaturas e menores valores de umidade relativa.

Os maiores valores de porcentagem de evaporação a que ocorreram foram obtidos nos meses de outubro, novembro, dezembro, janeiro e fevereiro. Nesses meses a incidência dos raios solares se faz com uma inclinação menor e a temperatura ambiente é superior aos outros meses do ano, ocasionando condições mais propícias à evaporação.

O procedimento 2 estipula que a inclinação seja fixada no valor da inclinação de $20,5^{\circ}$ e a vazão fixada no valor que melhor apresentou resultados de porcentagem de evaporação no procedimento 1 ou seja, a vazão deve ser fixada em 2,5 g/s. Esses resultados podem ser visualizados na Figura 3.

Figura 3 - Porcentagem de água evaporada em função do horário.

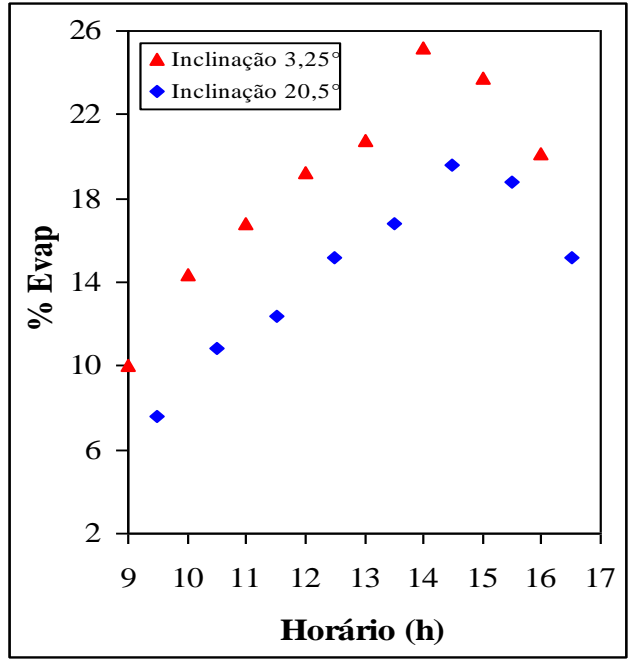

(a) Meses de: outubro, novembro, dezembro, janeiro e fevereiro.

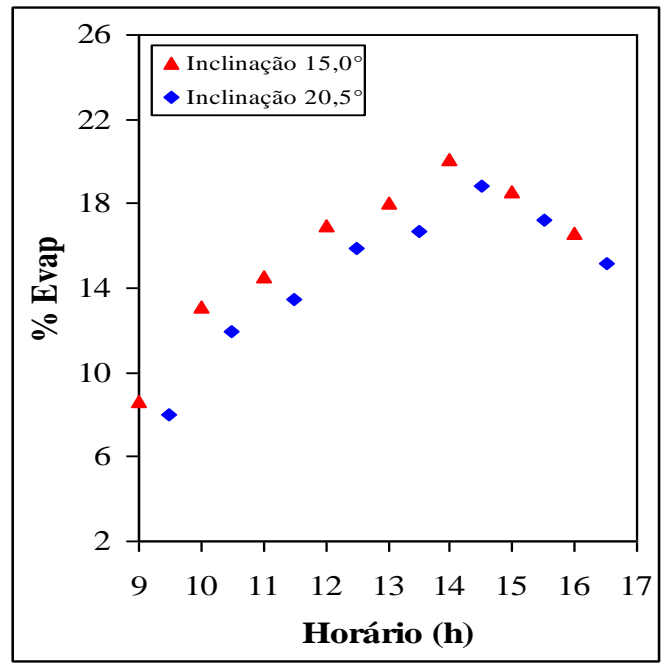

(b) Mês de março. 
Os resultados obtidos nos experimentos realizados nos meses de outubro, novembro, dezembro, janeiro e fevereiro podem ser vistos, na Figura 3 (a). Nestes meses os valores de porcentagem de evaporação quando se realiza o ajuste da inclinação são em média $29,7 \%$ superiores aos valores obtidos quando a placa plana permanece fixa.

Os resultados obtidos nos experimentos realizados no mês de março podem ser vistos na Figura 3 (b), onde nota-se que os valores mantendo a inclinação de $15^{\circ}$ são em média 8,0\% superiores aos valores obtidos se o equipamento fosse fixado em uma mesma inclinação

\section{CONCLUSÃO}

A partir dos experimentos verificou-se que é de primordial importância que seja realizado o ajuste mensal do coletor solar. Houve um aumento da taxa de evaporação para todos os meses em que esse ajuste foi realizado, chegando a valores de discrepância de até 36,4\%.

\section{REFERÊNCIAS}

BOX, G. E. P.; HUNTER, W. G.; HUNTER, J. S. (1978) Statistics for experimenters, an introduction to design, data analysis and model building. New York, John Wiley, 191p.

DUFFIE, J. A.; BECKMAN, W. A. (1980) Solar Engineering of Thermal Processes. USA: John Wiley \& Sons, 762.

HARTLEY, L. E.; MARTÍNEZ-LOZANO, J. A.; UTRILLAS, M. P.; TENA, F.; PEDRÓS, R. (1999) The optimization of the angle of inclination of a solar collector to maximize the incident solar radiation. Renewable Energy, v. 17, p. 291-309.

KALOGIROU, S. (2003) The potential of solar industrial process heat applications. Applied Energy, v.76, p. 337-361.

PALZ, W. (1980) Energia Solar e fontes alternativas. São Paulo: Hemus.358.

TIRIS, M.; TIRIS, C. (1998) Optimum Collector Slope and Model Evaluation: Case Study for Gebze, Turkey. Energy Conversion \& Management, v. 39, nº 3/4, p. 167-172. 